\title{
ENTREVISTA A ROSA COBO ${ }^{1}$
}

\author{
$\mathrm{M}^{\mathrm{a}}$ Elena Jaime de Pablos ${ }^{2}$
}

Rosa Cobo nació en La Cavada, localidad cántabra, en 1956. Estudió Enseñanza Secundaria en Vitoria y Madrid, y finalizó su formación académica en la Universidad Complutense, donde obtuvo la licenciatura y el doctorado en Ciencias Políticas y Sociología. Su tesis, "Democracia y Patriarcado en Jean Jacques Rousseau”, fue dirigida por otra insigne feminista Celia Amorós.

En la actualidad es Profesora Titular de Sociología en la Universidad de A Coruña, ocupación que compagina con la dirección del Centro de Estudios Feministas de esta institución y la dirección del Máster en Igualdad y Equidad en el Desarrollo de Cooperación que oferta, on line, la Universidad de Vic. También dirige la VI Edición del Curso de Historia de la Teoría Feminista en la Universidad de A Coruña

Entre sus numerosas publicaciones, destacan tres libros: Fundamentos del patriarcado moderno. Jean Jacques Rousseau (1995, Cátedra), Hacia una nueva política sexual. Las mujeres ante la reacción patriarcal (2011, Libros de la Catarata) y La prostitución en el corazón del capitalismo (2017, Libros de la Catarata). Son pilares fundamentales del pensamiento feminista contemporáneo tanto en España como en América Latina.

\footnotetext{
${ }^{1}$ Fecha de recepción: 29/11/2018.

Fecha de aceptación: 29/11/2018. ${ }^{2}$ Profesora Titular de Universidad, Departamento de Filología, Universidad de Almería; $\square$ mjaime@ual.es.
} 
Su labor feminista, ha sido reconocida con diversos galardones, entre ellos el Premio "Carmen de Burgos" de la Asociación de Estudios Históricos sobre la Mujer de la Universidad de Málaga, el Premio Igualdade "Ernestina Otero" del Consello Municipal da Muller de Vigo en 2017 o el Premio Comadre de Oro de la Tertulia Feminista Les Comadres en 2018.

¿A qué edad y por qué motivos comienzas a desarrollar una conciencia feminista?

Mi primer contacto con el feminismo fue en 1985, en unas jornadas que se celebraron en Madrid, "Mujeres, ciencia y práctica política", en las que intervenía Celia Amorós. Al año siguiente, en la presentación del libro que se hizo sobre las jornadas, le pedí a Amorós que me dirigiese la tesis y desde entonces estoy en el feminismo. Primero estuve formándome y después ya en la investigación y en la militancia feminista.

En tus publicaciones, cursos, seminarios, conferencias muestras un conocimiento profundo del fenómeno feminista y de las distintas corrientes que lo han vertebrado a lo largo de su historia, ¿podrías delimitar la vertiente ideológica en la que se encuadra el feminismo que tú defiendes?

El feminismo es un movimiento social y una poderosa tradición intelectual que tiene tres siglos de historia. La idea que ha vertebrado casi toda la historia del feminismo ha sido la de igualdad. El feminismo en el que yo me inscribo se articula alrededor de una idea material de igualdad. Y en esta misma dirección reivindico un feminismo con un nervio fuertemente anticapitalista. 
Existe cierto distanciamiento entre militantes de distintas corrientes feministas, pero también entre feministas de distintas generaciones, las más jóvenes no siempre encuentran referentes válidos en mujeres que han encarnado el movimiento feminista durante décadas, no les resultan tan cercanas como otras a las que siguen, por ejemplo, en blogs, redes sociales, youtube o demás medios de comunicación. ¿En qué radica este desencuentro generacional y cómo se puede minimizar?

Este último 8 de marzo, el de 2018, se llenaron las calles de mujeres jóvenes y mayores: mujeres de todas las edades clamábamos contra la violencia sexual. Es un hecho que el movimiento feminista está siendo ocupado por chicas jóvenes que reclaman su lugar. Y creo que se está consiguiendo. No niego que existan tensiones y conflictos entre distintos paradigmas o estrategias feministas y entre mujeres de diferentes generaciones, pero no es nada diferente a lo que ocurre en los demás movimientos sociales.

¿En qué medida influyeron las teorías feministas de Celia Amorós en la construcción de las tuyas propias?

Influyeron mucho por varias razones. En primer lugar, porque cuando yo me acerqué a Celia Amorós no sabía nada de feminismo. Todo lo que aprendí en el seminario "Feminismo e Ilustración" fue con ella. En segundo lugar, porque el feminismo de la igualdad del que Celia Amorós fue su principal teórica conectaba mucho con mi posición política en la izquierda. Me resultó fácil transitar de la igualdad a través de la que se organizaba el marxismo a la igualdad que articulaba el pensamiento feminista. 
¿Qué otras influencias consideras verdaderamente relevantes en tu concepción teórica y práctica del feminismo?

El feminismo radical y el marxista son los dos paradigmas a los que me siento más próxima intelectual y políticamente. Sin embargo, cuando comencé a estudiar la obra de Anibal Quijano y Souza Santos encontré algunas claves que me acercaron al pensamiento decolonial. Por otra parte, las pensadoras que han contribuido intelectualmente a crear el feminismo abolicionista también han sido muy relevantes a la hora de entender la configuración y el funcionamiento de los patriarcados contemporáneos.

Conoces en profundidad la obra del filósofo Jean Jacques Rousseau, objeto de estudio de tu tesis doctoral $y$ de varias de tus publicaciones, entre ellas Fundamentos del patriarcado moderno. Jean Jacques Rousseau (1995). ¿Qué puede inducir a una mente tan analítica como la de Rousseau a estructurar, de forma prejuiciosa, las bases de un dimorfismo sexual tan irreal e injusto como el que presenta en Emilio o de la Educación?

En Rousseau se cruzan dos teorías que parece imposible que puedan convivir juntas. De una parte, defiende una concepción fuerte de la igualdad como principio político y económico para organizar la vida social; y de otra, contribuye a la teoría de la inferioridad de las mujeres. Esa característica forma parte de una gran parte del pensamiento crítico. Defender la igualdad para los varones y la inferioridad para las mujeres es un rasgo muy común en la filosofía y en la teoría social y política, tanto en la liberal como en la marxista. Rousseau necesita que las mujeres estemos confinadas en el espacio doméstico y que nos ocupemos de todo el trabajo reproductivo y de cuidados 
para que los varones puedan cultivar su autonomía y desarrollar una ciudadanía muy activa.

En 1991 publicas, con Pepa Cruz Cantero, Las mujeres españolas: lo privado y lo público (C.I.S), un estudio pionero en el análisis de las barreras que impiden a las españolas alcanzar una situación de paridad con respecto a sus congéneres masculinos a finales del siglo pasado. De estas barreras, ¿cuáles permanecen a día de hoy tal cual se encontraban entonces?

Se han producido cambios en términos de qué grupos de mujeres tenemos más libertad, más autonomía, más acceso al mercado laboral y a la educación, pero a cambio otros grupos de mujeres están siendo más intensamente explotadas. La prostitución, los vientres de alquiler y la pornografía están produciendo focos nuevos de explotación económica y sexual que eran desconocidos hasta ahora.

En el libro Hacia una nueva política sexual. Las mujeres ante la reacción patriarcal (2011), analizas la naturaleza de los que llamas "nuevos bárbaros del patriarcado", ¿podrías definirlos y dar algunos ejemplos?

Los nuevos bárbaros del patriarcado son los que ejecutan violencia contra las mujeres, los responsables de las viejas y de las nuevas formas de violencia patriarcal. Son los que asesinan a mujeres que se quieren separar y a sus propios hijos e hijas para vengarse de la mujer que no acepta ser de su propiedad. También son bárbaros los puteros y proxenetas que explotan económica y sexualmente a mujeres que necesitan sobrevivir. Los que sacan beneficio de mujeres sin recursos para que gesten a quienes después registrarán como sus propios hijxs. Y los dueños de negocios y maquilas que explotan hasta extremos inimaginables la fuerza de trabajo de mujeres que no tienen 
recursos culturales ni económicos para sobrevivir de otra forma. Todos ellos forman ese ejército criminal que denomino nuevos bárbaros del patriarcado.

En La prostitución en el corazón del capitalismo (2017) aseguras que con la llegada del capitalismo neoliberal, el fenómeno de la prostitución pasa de ser una manifestación más del modo en el que el patriarcado aliena el cuerpo femenino para la obtención del placer masculino a ser un negocio enormemente lucrativo sustentado, casi siempre, "sobre la economía criminal" y el "tráfico de mujeres y niñas”. ¿Podrías resumir en breves líneas cuáles son las claves del éxito de este negocio en expansión?

Hasta hace poco más de tres décadas la prostitución estaba formada por un conjunto de pequeños negocios artesanales que no tenían ningún impacto económico. Hoy esos pequeños negocios se han transformado en una gran industria global, con un modo de funcionamiento propio de una gran multinacional. Burdeles, pisos, hoteles, agencias de turismo, locales de masajes, venta de artículos sexuales y el negocio de la pornografía, entre otros actores económicos, configuran una industria que en su mayor parte se desarrolla en el marco de la economía ilícita. La industria del sexo se ha convertido en una estrategia de desarrollo para algunos países y, a su vez, este negocio criminal permite a esos países engancharse a la economía global. Sin embargo, esta industria internacional se ha construido sobre una institución fundacional del patriarcado: poner a grupos de mujeres a disposición sexual de los varones. El capitalismo neoliberal ha tomado esta práctica patriarcal y la ha convertido en un negocio ilícito. 
Has dirigido un proyecto sobre prostitución y políticas públicas financiado por el Instituto de la Mujer. ¿Cuáles son los errores y los aciertos de las políticas públicas españolas en el tratamiento de este fenómeno social?

Necesitamos que el poder político se comprometa contra la explotación sexual. Necesitamos políticas abolicionistas. Es necesario desmantelar la industria del sexo, penalizar a proxenetas y puteros, y hacer políticas públicas de apoyo integral a las mujeres que están en prostitución.

La gestación subrogada o vientre de alquiler también implica poner el cuerpo femenino al servicio de otra u otras personas a cambio de dinero. ¿Cuál debe ser la respuesta feminista, a tu juicio, a esta técnica reproductiva regulada en países como Estados Unidos, Canadá, Rusia, Ucrania, Portugal, Grecia o India?

La respuesta feminista, como siempre, tiene que tener dos direcciones. Por una parte, la argumentación intelectual. Tenemos que explicar cuáles son nuestras razones para la crítica a los vientres de alquiler. Tenemos que argumentarlas bien con un lenguaje accesible para que las mujeres entiendan nuestra posición. Y, por otra parte, hay que hacer movilizaciones y acciones políticas en la sociedad y también a través del poder político cuando se tiene la posibilidad de acceder a ese poder. Los vientres de alquiler forman parte de ese proceso de mercantilización de los cuerpos de las mujeres que caracteriza el siglo XXI.

Desde el punto de vista sociológico, ¿cómo es posible que después de la campaña "Me Too" que ha conducido a millones de mujeres en Estados Unidos a manifestarse en contra del abuso sexual que tradicionalmente ha sufrido en silencio el sexo femenino, este país designara a Brett Kavanagh magistrado del 
Tribunal Supremo? ¿Puede otorgar crédito político, social o mediático el desprecio a un movimiento que aboga por la defensa de los derechos y de la dignidad de las mujeres en el llamado "primer mundo" en pleno siglo XXI?

Esa elección hay que inscribirla en el rearme ideológico de los neofascismos. Hay una evidente polarización social. Por una parte, hay más conciencia crítica feminista y más conciencia contra la brutalidad del capitalismo neoliberal, pero, por otra, hay una enorme preocupación en la derecha y en la extrema derecha porque están comprendiendo que se está gestando un profundo malestar entre sectores amplios de la sociedad. La precariedad laboral que está instalándose en nuestras sociedades y el aumento de las demandas de derechos de las mujeres y de otros sectores sociales explotados están alimentando el miedo de la derecha que, a su vez, intenta responder alimentando el miedo de los sectores más vulnerables de la sociedad.

He encontrado obras tuyas en bibliotecas extranjeras tan importantes como la British Library, pero en lengua española. ¿Se preocupan las editoriales españolas en traducir la obra de feministas británicas, estadounidenses, francesas o alemanas más que las editoriales extranjeras en traducir la obra de nuestras feministas? ¿No crees que la traducción en una herramienta imprescindible para establecer un diálogo intercultural entre un "ellas" y un "nosotras" en términos de igualdad?

La industria editorial, como el resto de las industrias, solo piensa en términos de beneficios. Y los textos feministas son relevantes para las editoriales en tanto son rentables. Sin embargo, afortunadamente, tenemos las redes sociales y mucho trabajo voluntario feminista que traduce textos sin cobrar nada, solo por convicciones éticas. 
Son las hackers del feminismo. El caso de Traductoras para la Abolición de la Prostitución es paradigmático en este sentido, pues decenas de traductoras traducen gratis textos relevantes para el abolicionismo. Tendremos que construir espacios alternativos al mercado para que circule el pensamiento crítico feminista. 